\title{
Filling Behavior of Wood Plastic Composites
}

\author{
Ivica Duretek, Thomas Lucyshyn and Clemens Holzer \\ Department of Polymer Engineering and Science, Montanuniversitaet Leoben, Leoben 8700, Austria
}

\begin{abstract}
WPC (wood plastic composites) are a young generation of composites with rapidly growing usage within the plastics industry. The advantages are the availability and low price of the wood particles, the possibility of partially substituting the polymer in the mixture and sustainable use of the earth's resources. The current WPC products on the market are to a large extent limited to extruded products. Nowadays, there is a great interest in the market for consumer products in more use of WPC as an alternative to pure thermoplastics in injection molding processes. This work presents the results of numerical simulation and experimental visualization of the mold filling process in injection molding of WPC. The 3D injection molding simulations were done with the commercial software package Autodesk ${ }^{\circledR}$ Moldflow $^{\circledR}$ Insight 2016 (AMI). The mold filling experiments were conducted with a box-shaped test part. In contrast to unfilled polymers, the WPC has reduced melt elasticity so that the fountain flow often does not develop. This results in irregular flow front shapes in the molded part, especially at high filler content.
\end{abstract}

Key words: Wood plastic composites, injection molding, simulation, process, mold.

\section{Introduction}

WPC (wood plastic composites) are highly filled thermoplastics; they are usually binary systems consisting of wood flour/spans/fibers and polymer matrix. These two main constituents are very different in origin, structure and performance. Polymers are high molecular weight materials whose performance is largely determined by its molecular architecture. The matrix polymers are typically low-cost commodity polymers that flow easily. The polymers tend to shrink and expand with temperature. Wood itself contains polymers such as lignin, cellulose, and various hemicelluloses but has very different properties from the synthetic polymers with which it is most often combined. Wood is less expensive, stiffer, and stronger than these synthetic polymers, making it a useful filler or reinforcement. Though wood does not shrink and swell much with temperature, it readily absorbs moisture. As with most natural materials, the anatomy of wood is complex. Wood is porous, fibrous, and anisotropic

Corresponding author: Ivica Duretek, Head of Material Data Determination, research fields: rheology, material data determination and powder injection molding.
[1].

WPC are a very young segment of the polymer industry with a great potential. Not only due to its flexible ratio of mixture and as a consequence, a flexible setting of mechanical properties, but also because of numerous benefits compared with pure wood. WPC have a higher biological, UV-radiation and weathering resistance and lower water absorption than conventional wood products and are less likely to be harmed by fungi, which results in lower maintenance costs. Furthermore, the WPC can be processed by commonly used plastics processing methods (e.g., injection molding, extrusion) which give a tremendous freedom of form and geometry. This gives a broad variety of possibilities regarding the shape of the product. Another benefit is the flexibility in visual appearance of WPC products achieved by post-manufactured brushing, embossing or shaping [2].

Wood fiber has lately attracted considerable attention as a filler to reinforce plastics, which has been driven by the continuous increase of oil prices and concerns of recycling. Wood fiber has advantages regarding density, cost, mechanical properties and biodegradability compared to other fibers. However, 
the density of wood fiber is still higher than plastics, such as polyethylene (PE) and polypropylene (PP).

The use of WPC in commercial products is limited today. The most frequent WPC products are to a large extent limited to extruded products. The use so far is a replacement of wood in outdoor railings and decking (Fig. 1) [3, 4]. In Europe, WPC are used in a wide variety of applications, from decking and siding to sophisticated musical instruments, furniture, watches, pencils, tableware, toys, decoration and pallets [5].

Injection molding is used more and more for the production of low-proportion NFC (natural fiber composites)_materials with up to $50 \%$ content of natural fibers by weight. A number of applications are currently undergoing commercial assessment, with the main focus on automotive applications (Fig. 2), where WPC materials have to compete with the talcum and glass fiber-filled compounds currently in use, as well as compression-molded NFC [5].

Although the WPC can be used for injection molding as a replacement of pure thermoplastics, there is a need to use its property to its full extent. While the market for extruded WPC products is growing with $10 \%$ per year [4], the injection molded WPC products are marginal. There is an unexploited potential for development [5].

Injection molding is one of the major processing technologies of polymers. Injection molding is widely used because of its economics to produce high volume of complex plastic articles [7]. It is a process where a plastic or composite is injected into a mold under very high pressure. This is done with an injection molding machine that consists of two main parts, the injector and the clamping device. The filling behavior and way the plastic flows into the mold are of paramount importance in determining the quality of the part [8].

The melt flow in the mold can be controlled by the design and manufacturing technology of the mold as well as by the processing conditions in order to obtain the molded parts with expected morphology, properties, shape, dimensions and surface. The cavity in the injection mold should be filled totally during the injection phase and the way of filling should be laminar and with a wide flow front. The stream flow (jetting phenomenon) should be avoided. Furthermore, the rheological phenomena occurring during the melt flow in injection molds must be known by the mold designers and controlled in the technological process [9].

Today's simulation tools allow the simulation of the filling, packing and cooling process and also a qualitative prediction of the part's shrinkage and warpage for semi-crystalline materials.

It helps to predict the problems that may occur due to wrong tool design or not optimized processing conditions [9]. According to Refs. [10-14], the mold filling can be divided into fountain flow and solid flow.

The fountain flow (Fig. 3) is typical for thermoplastic polymers and it is a result of wall contact by the melt and occurs due to the parabolic flow front [11]. The skin of the plastic in contact with the cool mold freezes rapidly, while the central core remains molten. When additional material is injected,

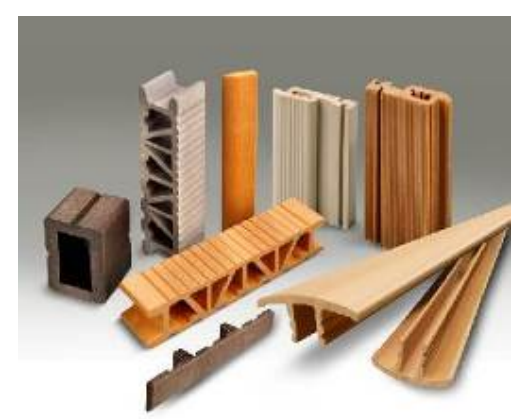

Fig. 1 Typical extruded semi-finished WPC products [6].

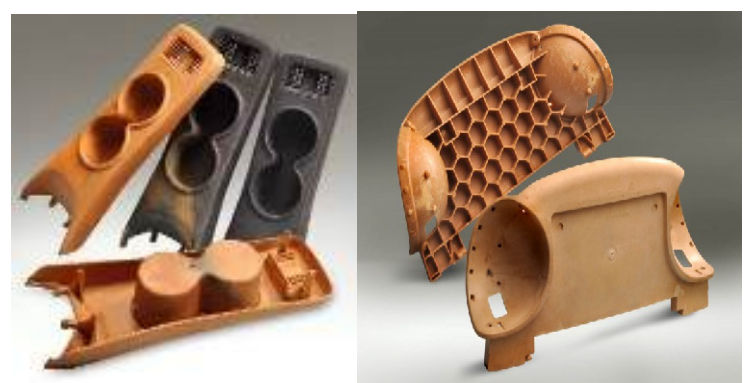

Fig. 2 Example of automotive applications for WPC [6]. 


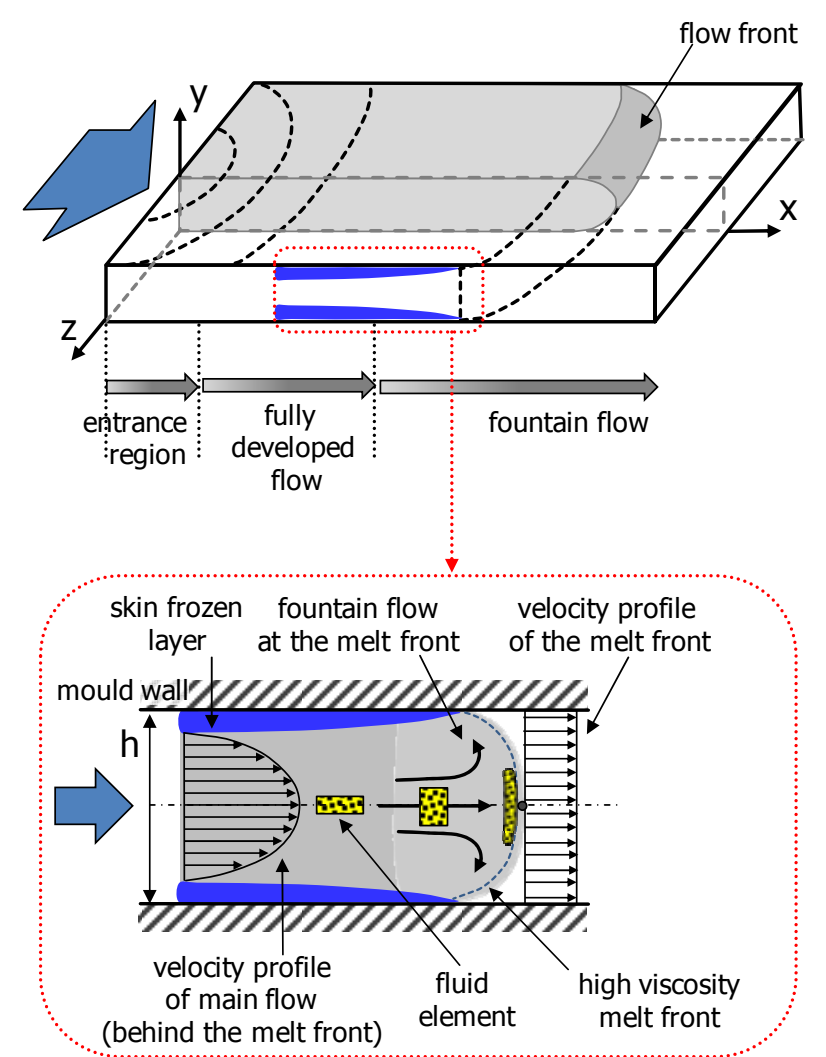

Fig. 3 Various flow regimes vs. cross section of the wall thickness, fountain flow (top) $[8,17,18]$.

it flows into this central core, displacing the material already there, which then forms a new flow front. The flow of this displaced material is a combination of forward flow and outward flow. The outward flow contacts the wall, freezes, and forms the next section of skin while the forward flow forms the new molten core. The frozen layer is formed by the flow front inflating, and so is subject to only a low shear stress and, therefore, has a very low level of molecular orientation.

Initially, the frozen layer is very thin, so heat is lost very rapidly. This results in more plastic freezing and the frozen layer getting thicker, cutting down the heat flow. After a time, the frozen layer will reach a thickness such that the heat lost by conduction is equal to the heat input from plastic flow and frictional heating, i.e., an equilibrium condition is reached [8].

The solid flow is typical for highly filled polymer compounds and thermosets $[11,15,16]$. By this flow, the melt slips on a layer of low viscosity resin. The flow front consists of less compacted melt followed by a compact melt zone. An orientation of reinforcing particles is not possible (Fig. 4) [11].

In this paper, the focus lies on the numerical simulation of the mold filling process in injection molding of two WPC types with various compositions using commercial simulation software and the experimental visualization with the help of a filling study.

\section{Materials and Methods}

\subsection{Materials}

For the experimental work, two different PP-based WPC were used. Fig. 5 shows the picture of pellets and light microscopy (LiMi) images of the investigated materials WPC-01 (Fig. 5a) and WPC-02 (Fig. 5b). From the LiMi image, the wood-matrix polymer interface can be seen. WPC-01 has a wood fiber content of $50 \mathrm{wt} . \%$. The viscosity of WPC- 02 is

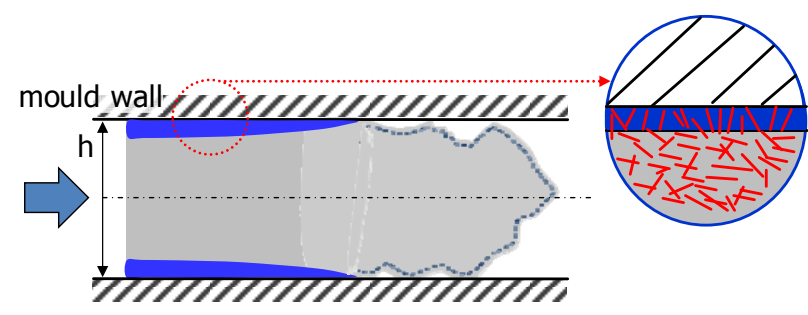

Fig. 4 Flow characteristic of highly filled polymers (bottom) [11].

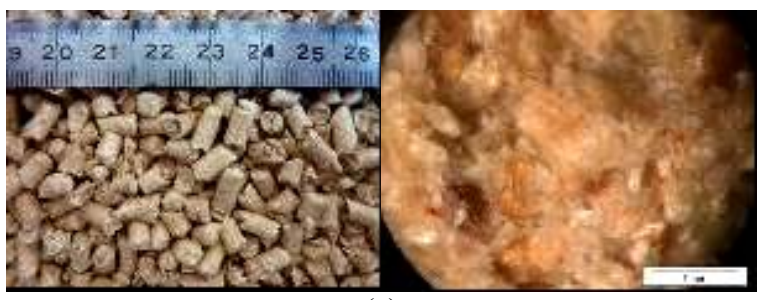

(a)

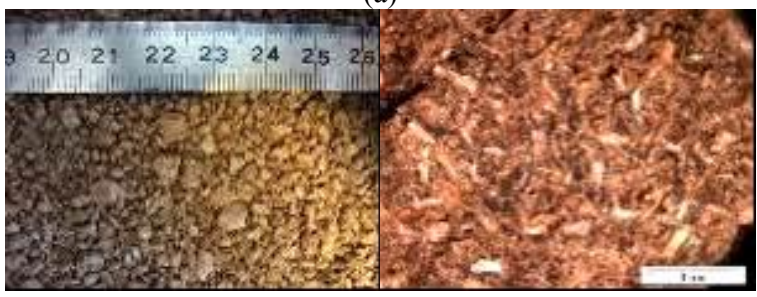

(b)

Fig. 5 Pellets of the investigated WPC and LiMi images: (a) WPC-01; (b) WPC-02. 
approx. 10\% higher than the viscosity of WPC-01 and the density is approx. $6 \%$ higher. A comparison of viscosity is shown in Fig. 6 and of density in Fig. 7.

\subsection{Injection Molding Experiments}

For comparing the simulation results with real parts, several test specimens were produced on an injection molding machine Arburg ALLROUNDER 470A 1000-400.

The mold used in this study was a box-shaped test part (stacking-box). The cavity is shown in (Fig. 8a). The mold was equipped with a hot runner system and the gate position was at the center of the box.

The process parameters for the injection molding tests were selected according to the processing instructions from the material manufacturer. For the filling study, the dosing volume was varied between $45 \mathrm{~cm}^{3}$ and $150 \mathrm{~cm}^{3}$ and the holding pressure was not applied. The other machine parameters are summarized in Table 1.

The materials were not pre-dried, they were stored in laboratory under normal storage conditions, at a temperature between $23{ }^{\circ} \mathrm{C}$ and $25^{\circ} \mathrm{C}$ and a humidity between $40 \%$ to $45 \%$. The residual moisture content of the materials was approxi. 3.3\%. The moisture content was measured with water content analyzer HydroTracer FMX (aboni $\mathrm{GmbH}$ fuer Mess- und Automatisierungstechnik, Germany).

\subsection{Filling Simulation}

The filling of the injection mold was investigated with the commercial software package Autodesk ${ }^{\circledR}$ Moldflow $^{\circledR}$ Insight 2016 (AMI). The process parameters from the experiment (Table 1) were used for the simulation. Simulations were performed with a 3D-mesh. The gating system for the mold was not modelled, but an injection point was directly set on the part. The model used for computation in AMI is presented in Fig. 8b.

The viscosity of the materials was measured with a Göttfert high pressure capillary rheometer using the slit die with flush mounted pressure transducers at two temperatures $\left(190^{\circ} \mathrm{C}\right.$ and $\left.200{ }^{\circ} \mathrm{C}\right)$ in a shear rate range

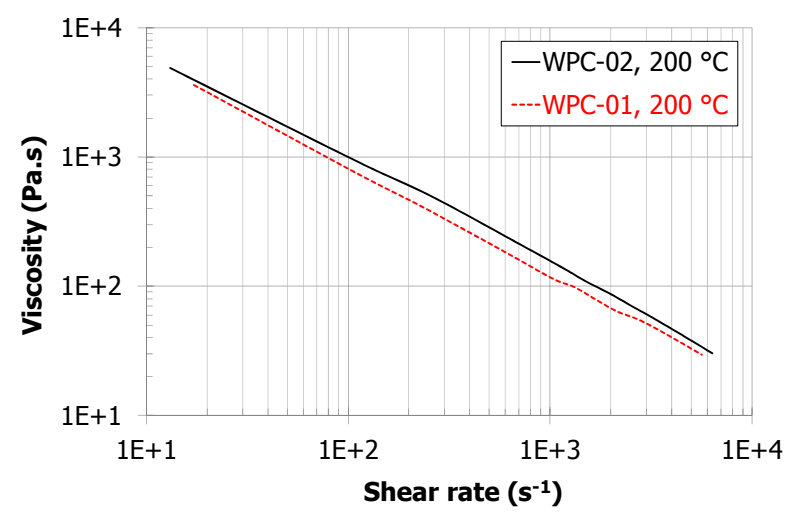

Fig. 6 Viscosity.

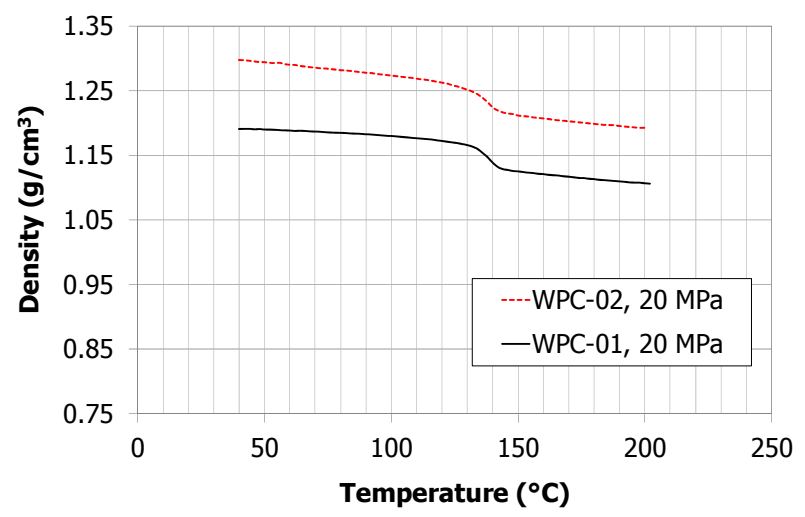

Fig. 7 Density.

Table 1 The most important parameters of the injection molding process.

\begin{tabular}{ll}
\hline Barrel temperatures $\left({ }^{\circ} \mathrm{C}\right)$, & $40-180-185-190-195$ \\
\hline Z0Hopper-Z1-Z2-Z3-Z4] & 200 \\
\hline Nozzle temperature $\left({ }^{\circ} \mathrm{C}\right)$ & 40 \\
Mold temperature $\left({ }^{\circ} \mathrm{C}\right)$ & 650 \\
Clamping force $(\mathrm{kN})$ & 50 \\
Back pressure $(\mathrm{bar})$ & 20 \\
Dosing speed $(\mathrm{m} / \mathrm{min})$ & 50 \\
Injection rate $\left(\mathrm{cm}^{3} / \mathrm{s}\right)$ & 25 \\
Cooling time $(\mathrm{s})$ & \\
\hline
\end{tabular}

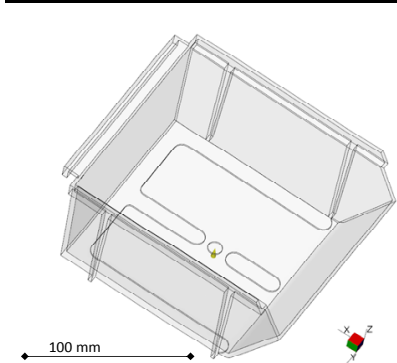

(a)

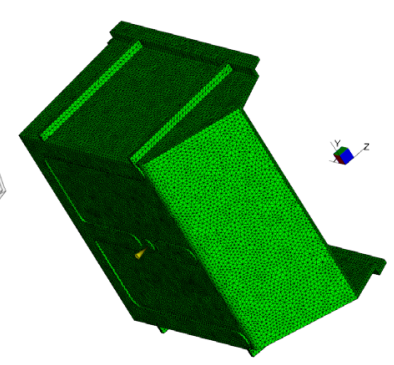

(b)
Fig. 8 Model of the mold cavity: (a): test part; (b): superimposed finite element mesh. 
between approx. 10 7,000 $\mathrm{s}^{-1}$. The viscosity model (Cross-WLF) was fitted from the corrected data (Weissenberg/Rabinowitsch) of these flow curves.

The viscosity measurements in the lower shear rate range $\left(<10 \mathrm{~s}^{-1}\right)$ using the parallel plate rotational rheometer were unsuitable for generating viscosity data. Due to the wall slip between the smooth plates and the polymer, the determination of rheological data was not possible.

\section{Results and Discussion}

The results of the experimental filling studies with WPC-01 and WPC-02 are shown in Figs. 9 and 10. It can be clearly seen that for both investigated WPC no classic fountain flow occurred (Fig. 3 (top)). The melt front has not the parabolic profile typical for thermoplastics. The flow front increasingly breaks up, is frayed and brittle.

Instead of the compact melt zone, the less compacted melt is folded and only at the end of the flow path compacted.

Furthermore, several repeated injection molding cycles showed bad reproducibility of the shape of the flow fronts (Fig. 11). The flow length was similar, but the shape of the flow fronts was different. In this regard, the various compositions of both WPC showed no obvious influence on mold filling.

In the case of pure PP as expected the fountain flow occurred in the cavity and finally the filling characteristics was uniform (Fig. 12a). For the unfilled PP the agreement between simulation and experimental measurement is excellent (Fig. 12b).

The simulation results of the filling behavior for WPC-01 are shown in Fig. 13a. The presentation contains the frame-by-frame recordings. The predicted melt front advancement, as well as weld lines is not in good agreement with the advancement pattern observed in the short shots of the molding. Unfortunately, the shape of the melt front could not be calculated satisfactorily.

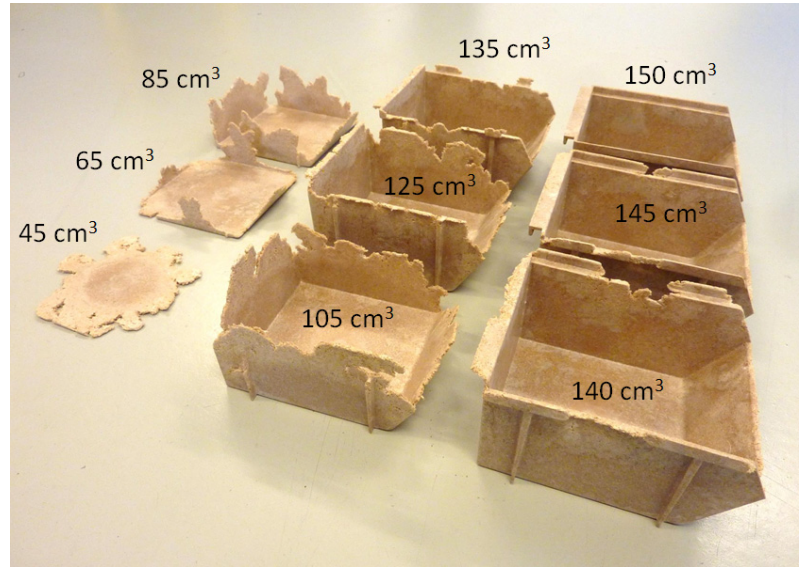

Fig. 9 Filling study with WPC-01.

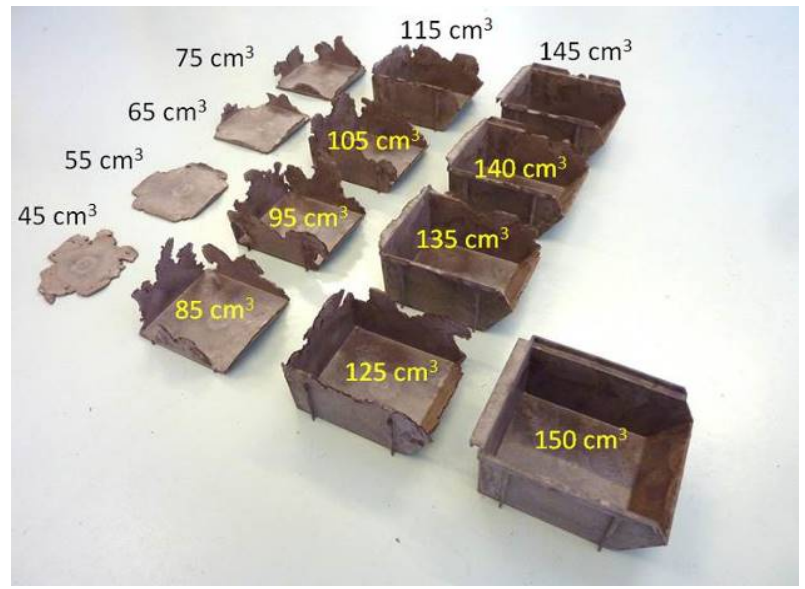

Fig. 10 Filling study with WPC-02.
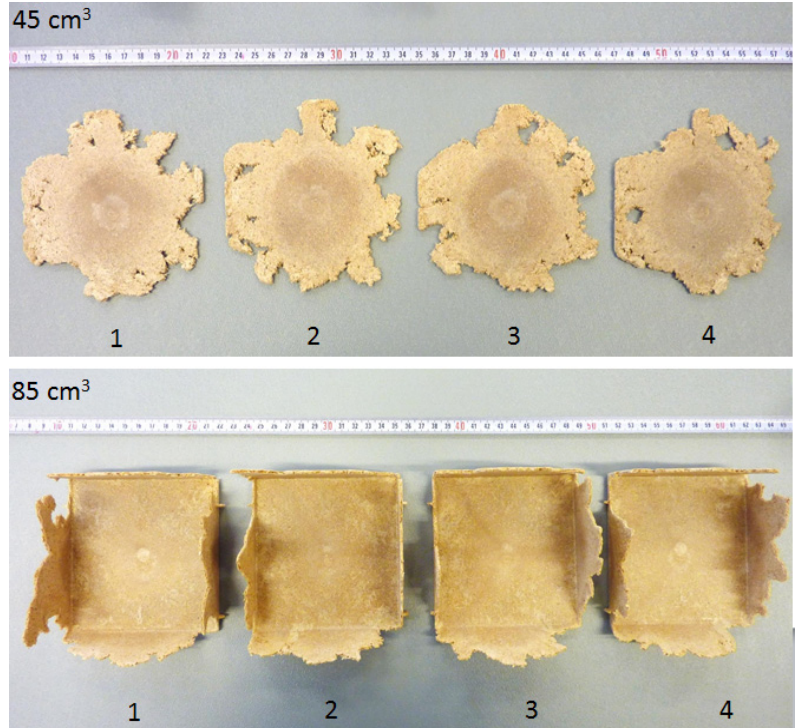

Fig. 11 Injection molded short shots of a WPC-01 in a mold for two different dosing volumes $\left(45 \mathrm{~cm}^{3}\right.$ and $\left.85 \mathrm{~cm}^{3}\right)$; four consecutive cycles. 

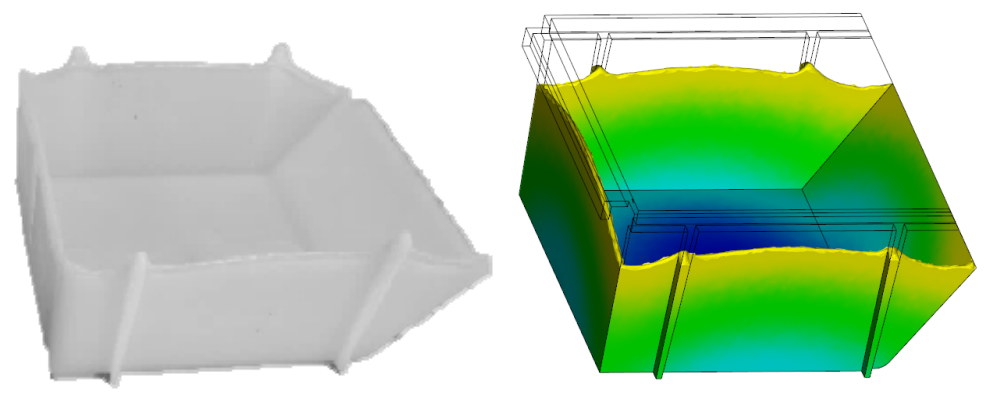

Fig. 12 Comparison of filling behavior for PP: (a) short shot; (b) simulation.
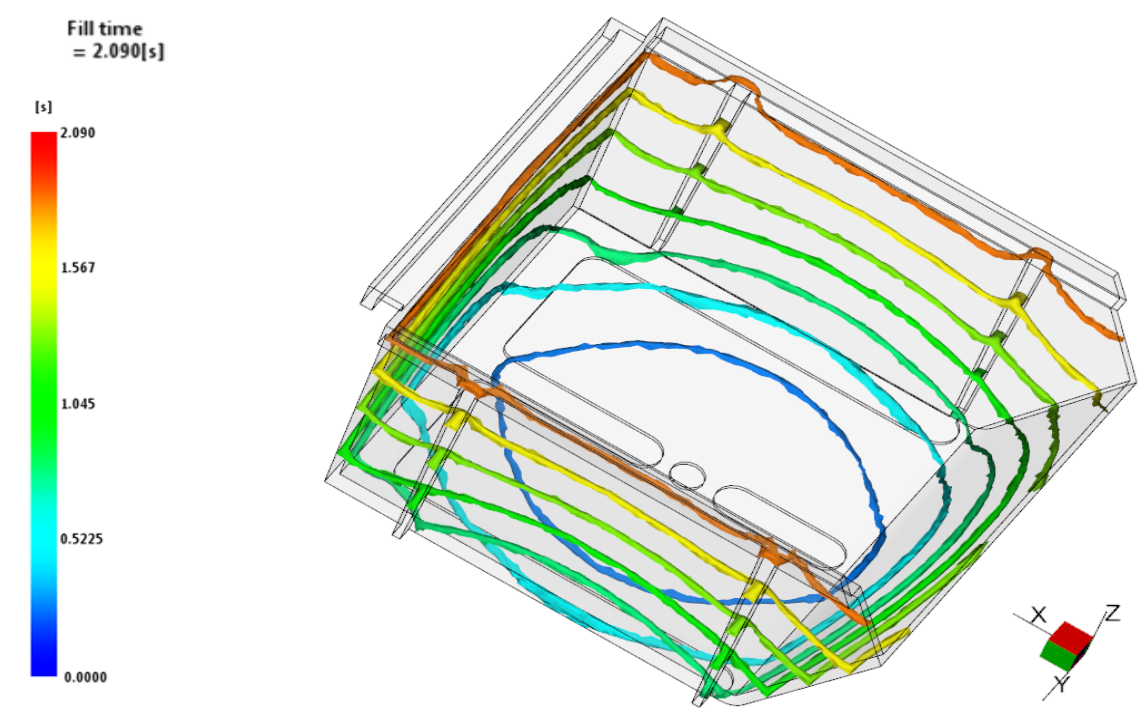

AUTODESK
MOLDFLW INSIGHT

(a)
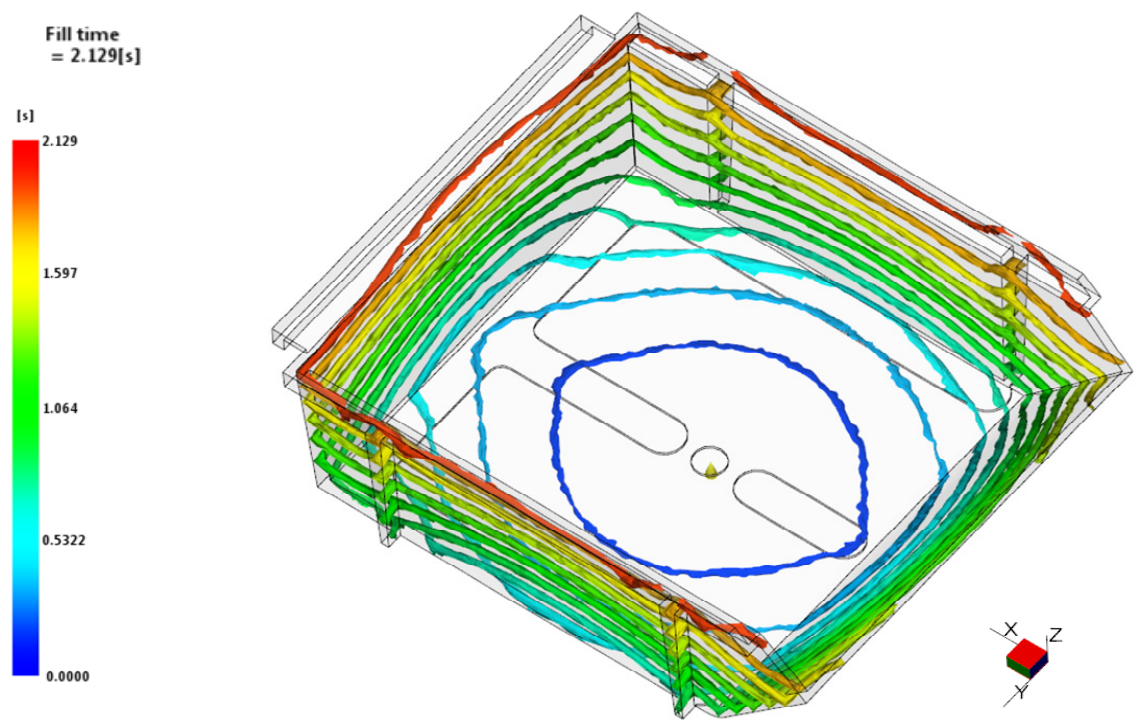

AUTODESK
MOLDFLW INSIGHT

(b)

Fig. 13 Flow front predicted with 3D-simulation for: (a) WPC-01; (b) WPC-02. 
The predicted melt-front advancement for the WPC-02 had a similar filling behavior as the results of WPC-01 (Fig. 13b).

The reasons for the bad agreement between experiment and simulation and the lack of fountain flow and further the occurrence of the irregular shape of the melt front may be attributed to the melt elasticity and the wall slip, which are not considered in the simulation model.

The high viscosity of WPC reduces the melt elasticity so that the fountain flow during the cavity filling often does not develop. The fountain flow effect occurs because the non-slip condition on the mold walls forces the material to flow from the center to the outward mold walls [19].

Furthermore, Funke [19] shows that the wall slip effect can be intensified by particular process settings, e.g., low melt and mold temperatures increase the material's wall slipping tendency.

As is well known, WPC tend to slip at the wall. In previous work [20-22], the influence of moisture content on the rheological characteristics of WPC was investigated. With the dried PP-based WPC with lower relative moisture content $(0.5 \%)$ shear flow occurred, whereas undried WPC with $3.8 \%$ relative moisture content showed existence of wall slip (pure plug flow). These results were obtained from by-pass extrusion rheometer and high pressure capillary rheometer at $200{ }^{\circ} \mathrm{C}$.

\section{Conclusions and Outlook}

This paper presents the results of numerical simulation and experimental visualization of the mold filling process in injection molding of WPC.

Due to low melt elasticity of highly filled WPC, the classic fountain flow like for unfilled thermoplastics did not develop. Melt front break and so called finger effects occurred. The shape of the melt front was unpredictable and not reproducible.

The filling behavior of WPC cannot yet be accurately predicted by using the 3D simulation software. In the case of highly filled thermoplastics like WPC, the simulation of mold filling processes requires different adjustments compared to the use of conventional thermoplastics (e.g., an adequate rheological model for wall slipping).

To exactly describe the shape of the flow front, filling stage simulation should use equations for the material properties which take into account the elastic extensional behavior of the melt.

Further investigations with WPC with different wood content will be done to identify possible effects (e.g., wall slip and moisture content) regarding flow and filling behavior. Furthermore, the influence of the filler size, shape and aspect ratio on the flow behavior will be investigated.

\section{Acknowledgments}

The authors would like to thank battenfeld-cincinnati Austria GmbH for supplying the -material used in this work.

This work is an extended paper of the presentation in the ic-rmm2, 2nd international conference on rheology and modelling of materials in Miskolc-Lillafüred, Hungary, October 5-9, 2015.

\section{References}

[1] Clemons, C. 2008. "Raw Materials for Wood Polymer Composites." In Wood Polymer Composites, edited by Niska, K. O., and Sain, M. Cambridge: Woodhead Publishing Limited.

[2] Kahr, S. C. 2010. "Wood Plastic CompositesDetermination and Comparison of the Specific Energy Consumption for WPC Compounding Methods Based on Two State-of-the-Art Formulations." Master thesis, Montanuniversitaet Leoben.

[3] Renard, C. 2011. "Injection molding WPC." Bachelor thesis, KTH Industrial Technology and Management, Stockholm

[4] Haider, A., and Eder, A. 2010. "Markets, Applications, and Processes for Wood Polymer Composites (WPC) in Europe." Presented at 1st International Conference on Processing Technologies for the Forest and Bio-based Products Industries 2010. Accessed April 11, 2011. http://conference.fh-salzburg.ac.at/fileadmin/files/docume nts/presentations/4B_Haider.pdf. 
[5] Haider, A. 2013. "The Market for Injection Moulded and Extruded WPC Products.” Accessed August 15, 2015. http://www.plastics.gl/consumer/the-right-mix/.

[6] JELU-WERK. 2011. "WPC-Anwendungen und Produkte.“ JELU-WERK Josef Ehrler GmbH \& Co KG Natural fibres, D-73494 Rosenberg. Accessed March 10, 2011. www.jeluplast.com/wpc-anwendungen/\#produktfo tos.

[7] Sina, L. T., Rahman, W., Rahmat, A. R., Tee, T. T., Bee, S. T., and Yu, L. C. 2012. "Computer Aided Injection Moulding Process Analysis of Polyvinyl Alcohol-Starch Green Biodegradable Polymer Compound." Journal of Manufacturing Processes 14: 8-19.

[8] Shoemaker, J. 2006. Moldflow Design Guide. Framingham: Moldflow Corporation Press.

[9] Bociaga, E., and Jaruga. T. 2007. "Experimental Investigation of Polymer Flow in Injection Mould." Archives of Materials Science and Engineering 28 (3): 165-72.

[10] Restrepo, J., and López, I. D. 2012. "Implementation of Highly Efficient Meshless Method for the Thermal Analysis of Fountain Flow during Filling in Injection Molding." In Proceedings of the 4SPE ANTEC 2012.

[11] Englich, S., Scheffler, T. and Gehde, M. 2013. "Mold Filling Behavior of Highly Anorganic Filled Phenolic Injection Moulding Compounds." In Proceedings of the 29th International Conference of the Polymer Processing Society (PPS 29).

[12] Thienel, P., Hoster, B., Schröder, K., and Ludwig, R. 1993. "Duroplast-Spritzgiessen mit Gasinnendruck." Kunststoffe 83: 91-5. (in German)

[13] Niemann, K. and Schröder, K. 1994. Spritzgiessen von Duroplasten. Heidelberg: Huethig Verlag.

[14] Li, C. S., Hung, C. F., and Shen, Y. K. 1994. "Computer Simulation and Analysis of Fountain Flow in Filling Process of Injection Molding." Journal of Polymer
Research 1 (2): 163-73.

[15] Thienel, P., Hoster, B., Bayerl, H., and Braun, U. 1990. "A Mould with a Window Allows Development of the Filling Pattern for Thermosetting Molding Compound." Kunststoffe 80 (12): 1346-50.

[16] Pfefferkorn, T. 2009. "Analyse der Verarbeitungs-und Materialeigenschaften Elektrisch Leitfaehiger Kunststoffe auf Basis Niedrig Schmelzender Metalllegierungen.” Ph.D. thesis, RWTH Aachen. (in German)

[17] Chung, T. N. 2001. "Stroemungsanalyse der Bindenahtformation beim Spritzgiessen von thermoplastischen Kunststoffen.“ Ph.D. thesis, Technische Universitaet Chemnitz. (in German)

[18] Dietz, W. and White, J. L. 1978. "Ein einfaches Modell zur Berechnung des Druckverlustes waehrend des Werkzeugfuellvorganges und der eingefrorenen Orientierung beim Spritzgiessen Amorpher Kunststoffe." Rheologica Acta 17 (6): 676-92. (in German)

[19] Funke, C., Albring, E. and Moritzer, E. 2010. "WPC has Different Filling Behaviour." Kunststoffe International 8: 53-6.

[20] Duretek, I., Friesenbichler, W., and Holzer, C. 2010. "New Insights into Characterization of Flow Properties of PP Based Wood Plastic Composites." In Proceedings of the 26th International Conference of the Polymer Processing Society (PPS 26).

[21] Hristov, V., Takacs, E., and Vlachopoulos, J. 2006. "Surface Tearing and Wall Slip Phenomena in Extrusion of Highly Filled HDPE/Wood Flour Composites." Polymer Engineering and Science 46 (9): 1204-14.

[22] Duretek, I., Selvasankar, R. K., Langecker, G. R., and Holzer, C. 2012. "Rheology of Wood Plastic Composites Using By-pass Extrusion Rheometer on the Twin Screw Extruder." In Proceedings of the 9th WPC-Natural Fibre and Other Innovative Composites Congress and Exhibition, AP1-AP8. 